\title{
Pathogenicity and Host-Parasite Relationships of Heterodera cruciferae in Cabbage
}

N. Sasanelli and N. Vovlas, Istituto per la Protezione delle Piante, Sezione di Bari, Consiglio Nazionale delle Ricerche, 70126 Bari, Italy; N. Trisciuzzi, Centro Ricerca e Sperimentazione in Agricoltura "Basile Caramia", 70010 Locorotondo (BA), Italy; and C. Cantalapiedra-Navarrete, J. E. Palomares-Rius, and P. Castillo, Instituto de Agricultura Sostenible, Consejo Superior de Investigaciones Científicas, Apdo. 4084, 14080-Córdoba, Spain

\begin{abstract}
Sasanelli, N., Vovlas, N., Trisciuzzi, N., Cantalapiedra-Navarrete, C., Palomares-Rius, J. E., and Castillo, P. 2013. Pathogenicity and host-parasite relationships of Heterodera cruciferae in cabbage. Plant Dis. 97:333-338.

Stunted cabbage ('Lupini') associated with severe soil infestations by a cyst-forming nematode were observed in large patches of open fields in Castellaneta, province of Taranto, southern Italy. Morphological traits based on mature cysts, males, and second-stage juveniles (J2s) and molecular analysis of ribosomal DNA (D2 to D3 expansion segments of $28 \mathrm{~S}$ and internal transcribed spacer [ITS]1 region) were used to identify the species. ITS1 sequence information supported the identity of Heterodera cruciferae, also showing a high degree of similarity to other species of the Heterodera Goettingiana group, including $H$. goettingiana, $H$. carotae, and $H$. urticae. Nematodes successfully established permanent feeding sites in cabbage roots which caused cellular alterations in the root cortex, endodermis, pericycle, and

vascular cylinder by inducing typical multinucleate syncytia. Syncytial cytoplasm was granular and dense, with variously sized vacuoles and hypertrophied nuclei with nucleoli. Cabbage plant growth was also reduced in pathogenicity tests. The relationship between the initial nematode population density in soil and shoot plant weight was well described by the Seinhorst's equation. Tolerance limits with respect to shoot plant weight of cabbage to $H$. cruciferae was estimated as 1.50 units of eggs plus $\mathbf{J} 2 \mathrm{~s} / \mathrm{cm}^{3}$ of soil. The minimum relative value $(m)$ for plant height was 0.71 at an initial nematode population density of $(\mathrm{Pi})$ $\geq 64$ units of eggs plus $\mathrm{J} 2 \mathrm{~s} / \mathrm{cm}^{3}$ of soil. The maximum nematode reproduction rate $(P f / P i)$ was 4.6 times that of the initial population density of 8 units of eggs plus $\mathrm{J} 2 \mathrm{~s} / \mathrm{cm}^{3}$ of soil.
\end{abstract}

Cabbage (Brassica oleracea var. capitata) has long been cultivated during cool seasons in temperate climates as an economically important vegetable crop in several Mediterranean countries (8). In Italy, it is widely cultivated (about 18,000 ha), especially in the southern regions. In the Mediterranean basin under field conditions, cabbage is usually transplanted in late summer and harvested in early spring. The diseases it can be affected by are those caused by plant-parasitic nematodes, which can cause severe damage $(1,20-23,28)$, particularly the cyst-forming species Heterodera cruciferae and $H$. schachtii $(2,4,17-19)$.

Damage to vegetable crops is influenced by specific Heterodera spp. and the initial nematode population density in soil at the time of sowing (24). Because Heterodera spp. are often host specific, precise identification and estimation of population density in soil are crucial for designing effective control measures in the context of sustainable and integrated pest management, and considering their long persistent dormant stage (eggs protected within cysts). It is well established that the extent of crop growth suppression is influenced by the nematode population density at sowing and that a minimum population density $(T)$ is required before measurable yield loss occurs (tolerance limit) $(25,26)$. Although damage caused by the cabbage cyst nematode $H$. cruciferae to cabbage is known in several growing areas such as Europe, California, Russia, South Australia, and Turkey $(4,6,9,11,19,29)$, some controversy exists regarding the pathogenicity, threshold levels, and host-parasite relationships on cabbage. Some authors have not considered $H$.

Corresponding author: P. Castillo, E-mail: p.castillo@csic.es

* The $\boldsymbol{e}$-Xtra logo stands for "electronic extra" and indicates that Figures 1 and 3 appear in color in the online edition.

Accepted for publication 4 September 2012.

http://dx.doi.org/10.1094/PDIS-07-12-0699-RE

(C) 2013 The American Phytopathological Society cruciferae to be a major pest of cabbage (29) but others have reported considerable crop losses $(18,33)$. The sugar beet cyst nematode $H$. schachtii has also been reported as damaging cabbage and occurring together in the same fields with $H$. cruciferae (28). Although $H$. cruciferae and $H$. schachtii have many common hosts, their host range is somewhat different, as is their pathogenicity on cabbage (18). Hence, proper identification is necessary for selecting control measures. Under glasshouse conditions, McCann (18) reported that $H$. schachtii and $H$. cruciferae reduced shoot and root growth of cabbage, with the former causing higher levels of damage. However, no data are available on the minimum population density of the cabbage cyst nematode determining the threshold for measurable yield loss (tolerance limit $T$ ) (25).

During early autumn 2010, severe feeder root infections of 'Lupini' cabbage and soil heavily infested (64 units of eggs and second-stage juveniles $[\mathrm{J} 2 \mathrm{~s}] / \mathrm{cm}^{3}$ of soil) by Heterodera spp. were found in fields at Castellaneta (Taranto Province) in southern Italy. Areas of affected plants occurred in patches within the field. Diseased plants showed damage that occurred in patches within the field, with symptoms including delayed formation of heads, severe stunting, and heavily affected root systems. The abundance of cystnematode-affected roots suggested a highly specialized nematodeplant interaction. Therefore, the objectives of this study were to determine (i) accurate identification of the nematode species, (ii) the histopathology of nematode-feeding sites, and (iii) the relationship between the initial soil nematode population density and growth of cabbage under greenhouse conditions.

\section{Materials and Methods}

Nematode identification. The cyst nematode isolate infecting cabbage roots was identified by morphology, as well as by molecular analysis of ribosomal DNA. Four samples of infected cabbage roots with soil of the associated rhizosphere as well as bulk soil were taken arbitrarily with a shovel from the upper $30 \mathrm{~cm}$ of soil from the field site in October 2010. Cysts, males, and J2s were extracted from soil (5), and adult white females and cysts were also recovered from root tissues, mounted in glycerin, and examined by 
light microscopy for diagnosis. To observe the vulval cone, the posterior end of a cyst was excised under a stereomicroscope and an approximately 100-by-100- $\mu \mathrm{m}$ section with intact fenestral area was excised and prepared for observation (32). Morphological differentiation was as described by Subbotin et al. (32). Mature cysts, including evaluation of at least 20 specimens, were characterized by features of the vulval cone including the bridge structure, shape of semifenestra, and presence or absence of bullae.

For molecular analyses, two young females were temporarily mounted in a drop of $1 \mathrm{M} \mathrm{NaCl}$ containing glass beads and, after taking measurements and photomicrographs of diagnostic characteristics, the slides were dismantled and DNA extracted. Nematode DNA was extracted from single individual female nematodes and polymerase chain reaction (PCR) assays were conducted as described by Castillo et al. (3). The D2 to D3 expansion segments of $28 \mathrm{~S}$ rDNA was amplified using the D2A (5'-ACAAGT ACCGTGAGGGAAAGTTG-3' $3^{\prime}$ and D3B (5'TCGGAAGGAACCAGCTACTA-3') primers (3). The internal transcribed spacer [ITS]1 region was amplified using forward primer TW81 (5' GTTTCCGTAGGTGAACCTGC-3') and reverse primer AB28 (5'-ATATGCTTAAGTTCAGCGGGT-3'), as described by Subbotin et al. (31).

PCR products were purified after amplification using ExoSAPIT (USB products; Affymetrix), quantified using a Nanodrop spectrophotometer (Nanodrop Technologies), and used for direct sequencing in both directions using the primers described above. The resulting products were purified and run on a DNA multicapillary sequencer (Model 3130XL Genetic Analyser; Applied Biosystems), using the BigDye Terminator Sequencing Kit (v.3.1; Applied Biosystems), at the Servicio Central de Apoyo a la Investigación (SCAI), University of Córdoba sequencing facilities (Córdoba, Spain).
Histopathology. Roots of 'Lupini' cabbage plants naturally infected by $H$. cruciferae were selected for histopathological studies. Roots were gently washed free of adhering soil and debris, and root portions with single nematode infections were selected together with uninfected healthy roots. Tissues were fixed in formaldehyde chromo-acetic solution for $48 \mathrm{~h}$, dehydrated in a tertiary butyl alcohol series $(40,70,85,90$, and $100 \%)$, embedded in paraffin with a melting point of $58^{\circ} \mathrm{C}$, and sectioned with a rotary microtome. Sections 10 to $12 \mu \mathrm{m}$ thick were placed on glass slides, stained with safranin and fast-green, mounted permanently in a $40 \%$ xylene solution of a polymethacrylic ester (Synocril 9122X; Cray Valley Products), examined microscopically, and photographed (13).

Relationship between inoculum density and plant growth. Inoculum of $H$. cruciferae was produced on 'Lupini' cabbage inoculated as described below and maintained in a greenhouse adjusted to $20 \pm 2{ }^{\circ} \mathrm{C}$. After 2 months, cysts were numerous and mature (brown), inoculated plants were removed from pots and their roots vigorously washed free of adhering cysts and soil; then, cysts then extracted from soil by the routine sieving-decanting method (7). Extracted cysts retained on the $250-\mu \mathrm{m}$-pore sieve were counted and crushed to estimate their egg content (27). Numbers of cysts in the appropriate proportion to give population densities of $0,0.25$, $0.5,1,2,4,8,16,32,64,128,256$, and $512 \mathrm{eggs} / \mathrm{cm}^{3}$ of dried soil were mixed thoroughly with autoclaved $\left(121^{\circ} \mathrm{C}\right.$ for $1 \mathrm{~h}$; twice) sandy soil mixture $(\mathrm{pH} 7.2$, sand $>99 \%$, silt $<1 \%$, clay $<1 \%$, and organic matter $=0.75 \%$ ) to obtain the desired inoculum density for experiments; $700-\mathrm{cm}^{3}$ clay pots were filled with the infested soil mixtures. A single 4-week-old Lupini cabbage seedling was transplanted into each pot. The pots were arranged on benches in a greenhouse at $20 \pm 2{ }^{\circ} \mathrm{C}$ in a randomized complete block design with five replications for each population density. The experiment was performed twice. Plants in pots were watered as needed and

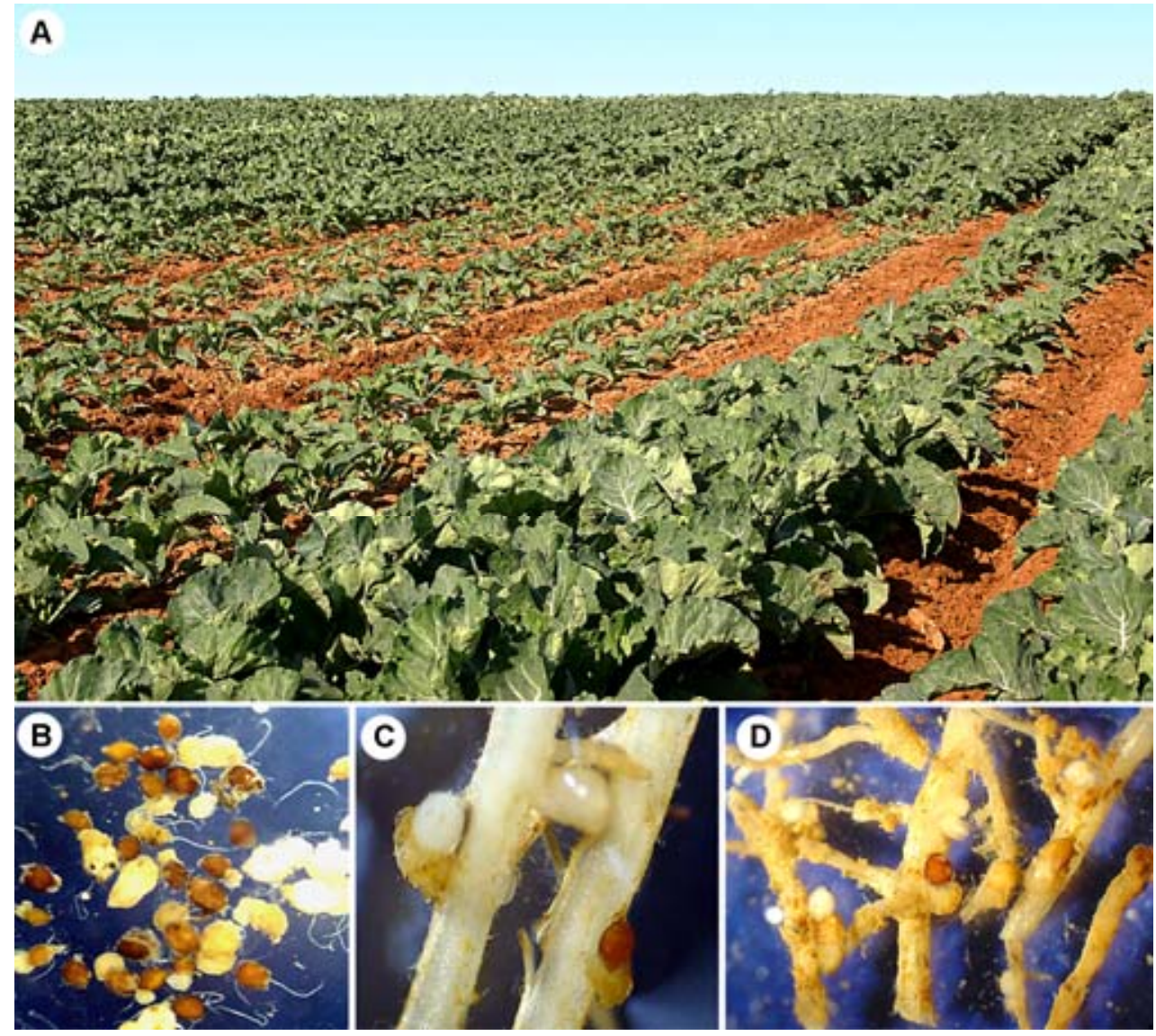

Fig. 1. Field symptoms and cabbage roots infected by the cabbage cyst nematode Heterodera cruciferae. A, Commercial field of 'Lupini' cabbage in Castellaneta, southern Italy, showing a patch severely damaged by the nematode. B, Live males, females, and cysts of the nematode. C and D, Details of cabbage roots infected by the nematode showing mature cysts (brown) and adult females (white). 

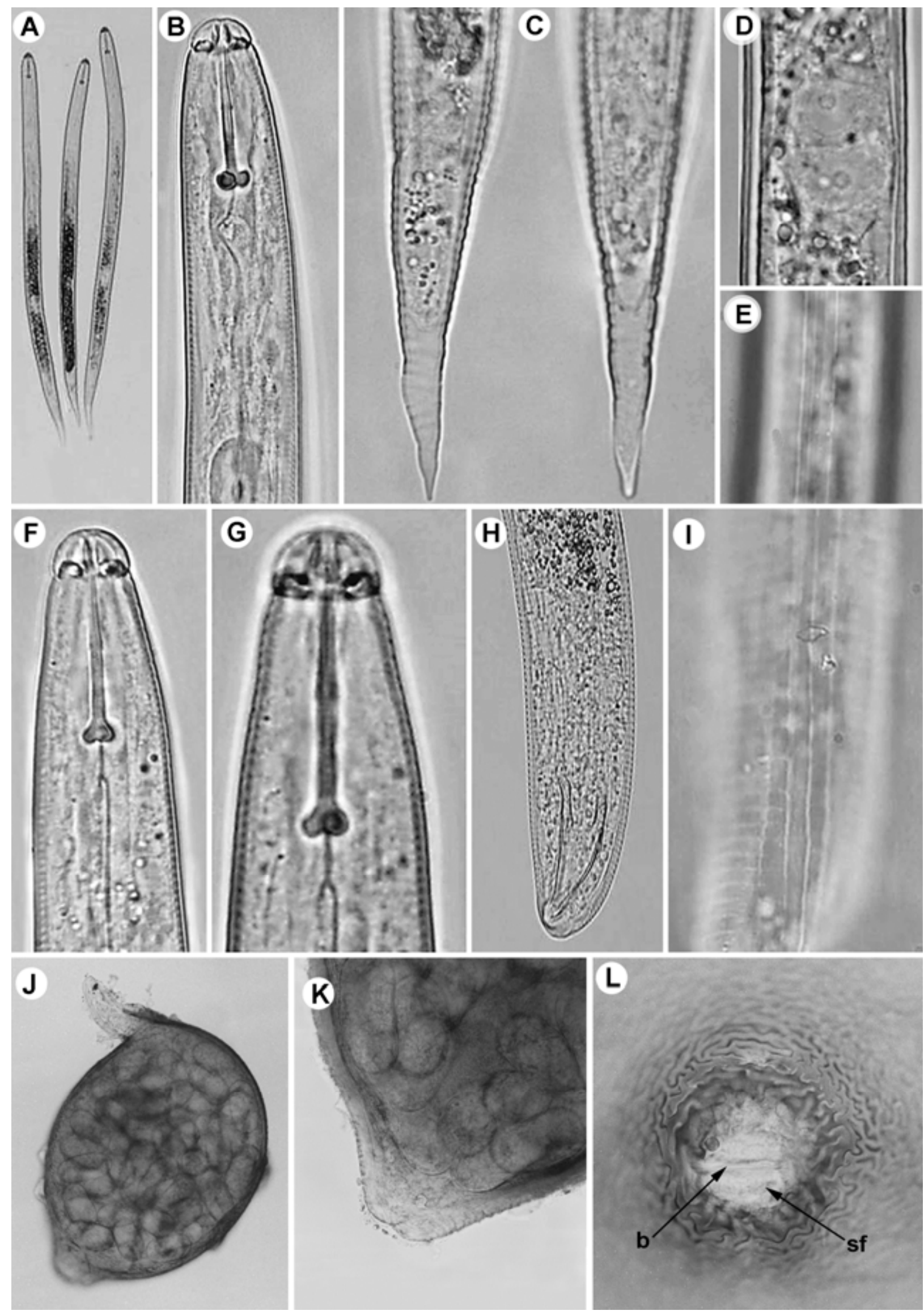

Fig. 2. Details of diagnostic features of the cabbage cyst nematode Heterodera cruciferae. A, Entire infective second-stage juveniles (J2s). B, Anterior region of J2. C, Tail region of J2. D, Genital primordium of J2. E, Lateral fields of J2. F and G, Anterior body regions of male. H, Posterior body portion of male. I, Detail of male lateral fields. J, Entire cyst filled with eggs. K, Vulval cone. L, Cyst vulval cone showing semifenestra (sf) and bridge (b). 
were fertilized once a week with $100 \mathrm{ml}$ of a $0.1 \%$ 20-5-32+ micronutrients hydro-sol fertilizer solution (Haifa Chemicals Ltd.). Data on the appearance of symptoms of nematode attack (stunting of plant shoot growth) were recorded at 15- to 20-day intervals during the experiment. Fifty-five days after transplanting, plants were removed from pots, roots were washed free of adhering soil, and plant weights were recorded. Final nematode population density in the soil of each pot was determined by processing $500 \mathrm{~cm}^{3}$ of soil by Fenwick's method (7). Cysts and eggs in the soil were counted and final nematode population density $(P f)$ in each pot was determined. The reproduction rate $(P f / P i)$ was also calculated for each initial nematode population density.

Data analysis. The relationship between the initial nematode population density $(\mathrm{Pi})$ and plant growth (estimated by the shoot plant weight) was determined by fitting the data to the Seinhorst model: $y=m+(1-m) z^{P-T}$, with $P>T$, and $y=1$ when $P \leq T$ $(24,25)$. In this model, $y=$ relative value of the plant growth parameter; $m=$ the minimum value of $y$ ( $y$ at a very large initial nematode population density); $P$ is the initial nematode population density; $T=$ the tolerance limit (initial population at which plant growth is not impaired; and $z$ is a constant $<1$ reflecting nematode damage, where $z^{-T}=1.05(25,26)$. The Seinhorst's equation was fitted using the SeinFit program (35). The coefficient of determination $\left(R^{2}\right)$ and the residual sum of squares were used to indicate the goodness-of-fit of data to the model. Similarity between the experiments was tested by preliminary analyses of variance using experimental runs as factors. All runs gave the same results. That allowed determination of the experiment-treatment interaction; this interaction was not significant $(P \geq 0.05)$ and allowed data to be combined for analyses of variance and fitting to the Seinhorst's model. These included analyses of variance using Statistix 9.0 (NH Analytical Software).

\section{Results}

Field symptoms, nematode diagnosis, and molecular characterization. Lupini cabbage plants in commercial open fields at Castellaneta infected by the nematode showed patched distribution of field damage with severe decline, stunting, and heavily infected roots (Fig. 1) that were short and bushy due to secondary root production. Roots of infected plants had mature cysts and adult females visible on the root surface and in the soil (Fig. 1B-D). Population density in naturally infested soil ranged from 186 to 534 units of eggs plus J2s external to the cysts and 36 to 102 mature cysts per $100 \mathrm{ml}$ of soil. Cysts contained an average of 216 eggs each. A large, gelatinous egg sac matrix was typically associated with cysts and contained a limited number of eggs (ranging from 0 to 38) (Fig. 1B-D).

Mature cysts of Heterodera spp. from cabbage roots were light to dark brown, broad to lemon shaped, and had a vulval cone characterized by a long vulval slit $(>30 \mu \mathrm{m})$, ambifenestrate with low semifenestral arches, narrow vulval bridge and underbridge, and no bullae (Fig. 2). Males were characterized by a lip region offset and five to six annuli, stylet 22 to $28 \mu \mathrm{m}$ long, stylet-knobs rounded and posteriorly directed, and spicules ventrally curved and 32 to 36 $\mu \mathrm{m}$ (Fig. 2). J2 body length was 360 to $510 \mu \mathrm{m}$ (mean $428 \mu \mathrm{m}$ ); stylet length was 21.5 to $25.5 \mu \mathrm{m}$ (mean $23.5 \mu \mathrm{m}$ ) with rounded or slightly concave stylet knobs; tail tapered uniformly to a finely rounded terminus 39 to $55 \mu \mathrm{m}$ long (mean $48 \mu \mathrm{m}$ ) with hyaline region 18 to $31 \mu \mathrm{m}$ (mean $25 \mu \mathrm{m}$ ); and lateral field had four incisures (Fig. 2).

Amplification of ITS1 and D2 to D3 expansion segments of 28S rDNA yielded single fragments of approximately 1,000 and 700 $\mathrm{bp}$, respectively, based on gel electrophoresis. The newly obtained sequences were submitted to GenBank (accession numbers JX402414 and JX402415, respectively). ITS1 of $H$. cruciferae from open fields of cabbage at Castellaneta (JX402415) matched well (99\% similarity) with ITS1 sequence of $H$. cruciferae (AF274411 and GU126667) from the Netherlands and Russia, respectively $(4,31)$. In addition, ITS1 sequence from Castellaneta matched well (99\% similarity) with $H$. carotae (AY347917 and AF274413) from Italy and France $(16,31)$ and $H$. urticae (AF274412) from Belgium (31). D2 to D3 expansion segments of $28 \mathrm{~S}$ rDNA of $H$. cruciferae from Castellaneta (JX402414) matched (99\% similarity) with the D2 to D3 sequences of H. glycines from

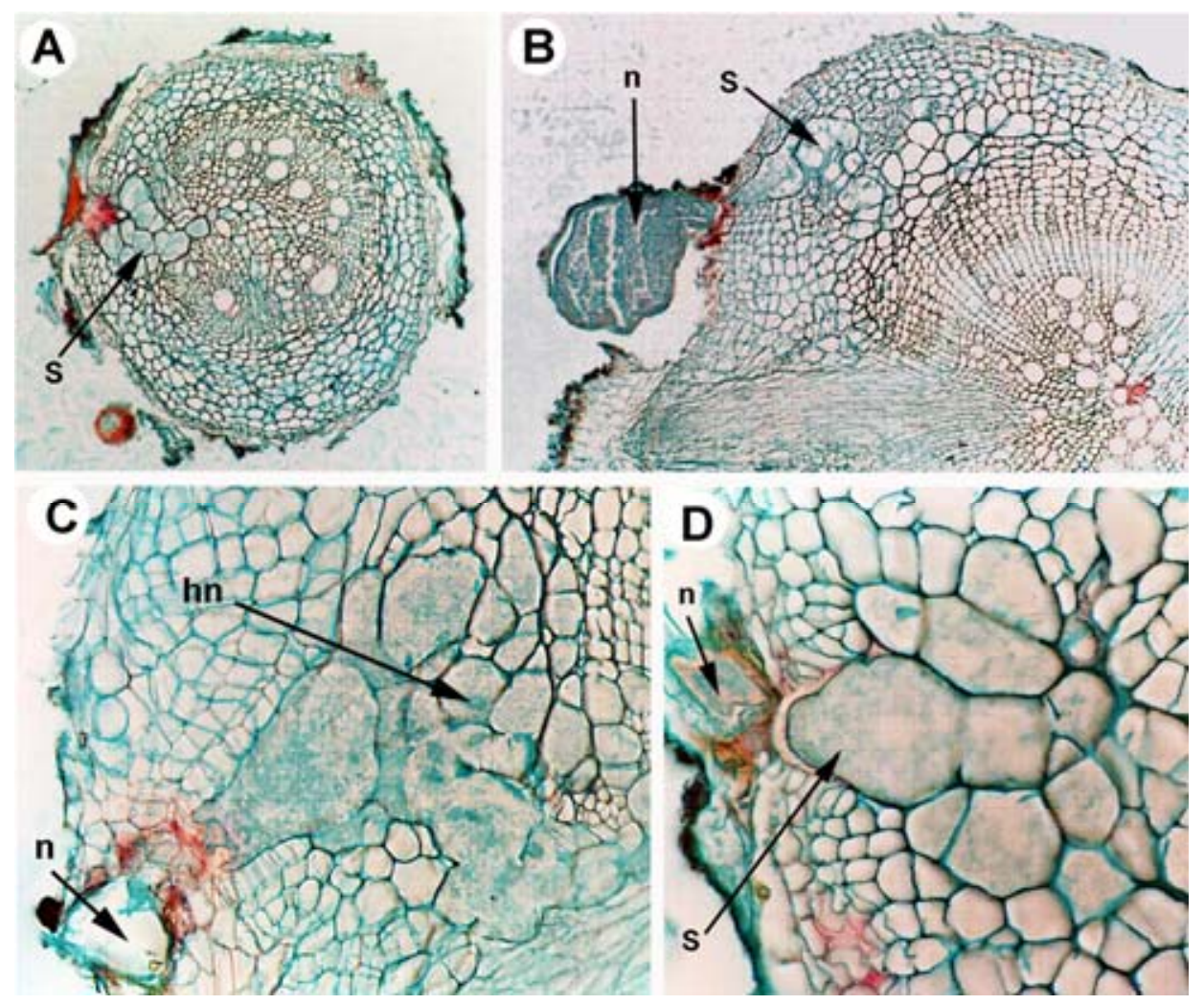

Fig. 3. Histopathology of Heterodera cruciferae in naturally infected roots of 'Lupini' cabbage. A-D, Transverse sections of cabbage roots (Lupini) infected by $H$. cruciferae showing the semi-endoparasitic adult female $(\mathrm{n})$ inducing the cortical and stellar syncytium (S) showing fused syncytial cells with dense cytoplasm and hypertrophic nuclei (hn) 
China deposited in GenBank (GU595451 [D. Peng and W. Ye, unpublished], HM560852 [W. Ye, D. Peng, and B. Xu, unpublished], and JN684906 [Z. Wei, H. Li, Y. Liu, and M. Li, unpublished]) and matched (99\% similarity) with $H$. schachtii (GU475088) from Iran (R. Heydari, Z. Tanha Maafi, and E. Pourjam, unpublished).

Histopathology. The histopathology and parasitic habit of Lupini cabbage seedlings to infection of $H$. cruciferae revealed a typical susceptible reaction: cellular alterations in the root cortex, endodermis, pericycle, and vascular cylinder caused by the expanding bodies of the nematode females (Fig. 3). Syncytial cytoplasm was granular and dense and contained several vacuoles of various sizes and hypertrophied nuclei and nucleoli (Fig. 3). These included extensive multinucleate syncytial with granular dense cytoplasm, thickened cell walls near the nematode lip region, and many interrupted sectors between walls of components of the syncyctium.

Relationship between inoculum density and plant growth. The isolate of $H$. cruciferae reduced cabbage plant growth. Data from the two runs of the experiment were combined because the run-treatment interaction was not significant $(P \geq 0.05)$. The relationship between the initial soil nematode population density and shoot plant weight was well described by Seinhorst's equation (Fig. 4). Statistics for fitting the model of shoot plant weight was $R^{2}=0.86$, sum of squares error $=1.123$ (Fig. 4). Stunting and reduction of plant shoot growth was apparent 30 days after inoculation, with an initial population density of only 4 units of eggs and $\mathrm{J} 2 / \mathrm{cm}^{3}$ of soil. All plants inoculated with more than 2 eggs and $\mathrm{J} 2 / \mathrm{cm}^{3}$ of soil showed symptoms and clearly showed progressive stunting at 45 days after inoculation. A tolerance limit (T) for Lupini cabbage plants to $H$. cruciferae was estimated at 1.50 units of eggs and $\mathrm{J} 2 / \mathrm{cm}^{3}$ of soil for shoot plant weight. The minimum relative values $(\mathrm{m})$ for shoot plant weight were 0.71 at $\mathrm{Pi}$ $\geq 64$ units of eggs and $\mathrm{J} 2 / \mathrm{cm}^{3}$ of soil. The maximum nematode reproduction rate $(\mathrm{Pf} / \mathrm{Pi})$ was 4.6 at an initial population density $(P i)$ of 8 units of eggs and $\mathrm{J} 2 / \mathrm{cm}^{3}$ of soil (Table 1).

\section{Discussion}

Cyst nematodes are very destructive to many vegetables and may considerably reduce yield (32). Accurate identification of Heterodera spp. is a prerequisite for an appropriate and effective management of these nematodes in cabbage. Similarly, knowledge of the relationship between initial nematode population densities

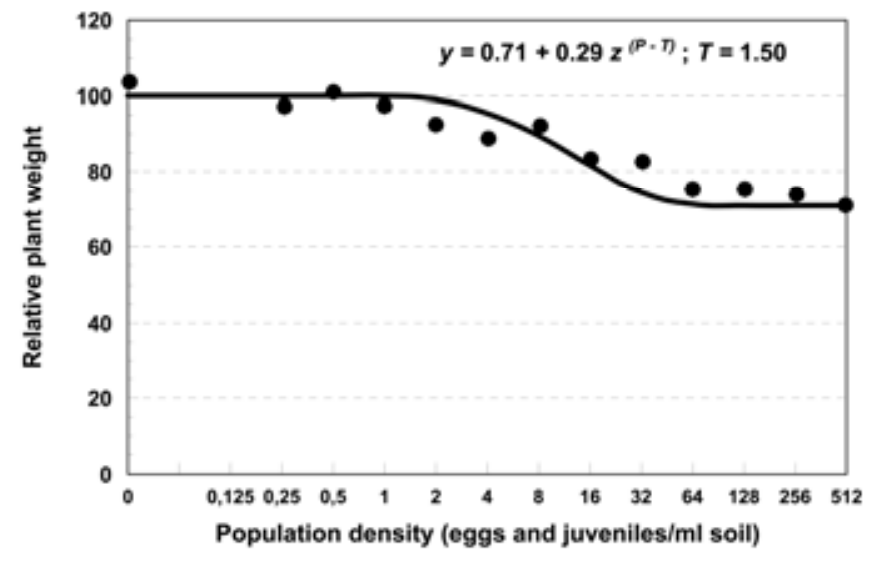

Fig. 4. Relationship between initial population densities $(P i)$ of Heterodera cruciferae and relative shoot plant weight of 'Lupini' cabbage plant growth $(Y)$ in pots at $20 \pm 2^{\circ} \mathrm{C}$ in a greenhouse for 55 days. Each point is the mean of two trials with five replicated plants each. Line represents the predicted function calculated by fitting the Seinhorst's model to data of shoot plant weight. Abbreviations: $y=$ relative value of the plant growth parameter (ratio between the values of growth parameters at a given $P$ and that at $P \leq T) ; z=$ a constant $<1$ reflecting the host-parasite relationship, with $\tau^{T}=1.05 ; P=$ initial population density ( $\mathrm{x}$ axis); and $T=$ tolerance limit. Statistics for fitted models of shoot plant weight were $R^{2}=0.86$, sum of squares error $=1.123$. and plant growth is essential for prediction of crop losses caused by plant-parasitic nematodes and for selection of suitable management strategies. These include a limited range of registered chemical pesticides and low availability of resistant cultivars. In this research, the large numbers of eggs, J2s, and cysts recovered from naturally infected cabbage roots and associated soil in commercial production fields of southern Italy, as well as pathogenicity tests, indicated a successful host-parasite relationship between $H$. cruciferae and cabbage, as previously reported $(15,18)$. Molecular data of $H$. cruciferae suggested that ITS1 showed a limited resolving power for delimiting species of the Goettingiana group, including $H$. goettingiana, $H$. carotae, $H$. urticae, and $H$. cruciferae. These results agree with Subbotin et al. (30), who generated PCR-ITS restriction fragment length polymorphism profiles using 26 restriction enzymes for $H$. cruciferae, although it was not distinguishable from some profiles of $H$. carotae. Thus, more extensive molecular analyses of additional taxa and combined analyses of the ITS1 region with other molecular markers may help to improve molecular identification of these species (31). Consequently, morphology and morphometrics can separate $H$. cruciferae from $H$. carotae (by the shorter $\mathrm{J} 2$ tail and shorter vulval slit in the former) and $H$. goettingiana (by the shorter $\mathrm{J} 2$ tail and shorter cyst length in the former) species until new species-specific markers become available.

Our observations on comparative histological sections of healthy and $H$. cruciferae-infected cabbage roots confirmed a typical susceptible reaction (12,32). The development and parasitic habit of $H$. cruciferae that we observed in cabbage were similar to those found in other vegetables crops (32). Feeding sites are metabolic sinks sequestering nutrients from the host plants and limiting water and nutrient translocation from infected roots to aboveground plant tissues (10). Results also suggested that these infections support successful cyst nematode reproduction that increases the soil inoculum for the next growing season. The results obtained also showed that the threshold damage of cabbage by $H$. cruciferae (1.50 units of eggs and $\mathrm{J} 2 / \mathrm{cm}^{3}$ of soil) was significantly lower than those reported by McCann (18) in cabbage (40 cysts $/ 100 \mathrm{~cm}^{3}$ of soil) or those reported in cauliflower ( 25 units of eggs and $\mathrm{J} 2 / \mathrm{cm}^{3}$ of soil) (33). The lower tolerance limits described above suggested that $H$. cruciferae has the potential to severely damage cabbage under Mediterranean environmental conditions, particularly during warm autumn growing seasons; as for other cyst nematodes, warm temperatures increase its development and reproduction (34). Because cabbage is also severely damaged by other soilborne pathogens, including fungi, bacteria, and plant-parasitic nematodes $(2,4,17,18,22,23,36)$, adequate management procedures need to be implemented in order to prevent losses during cabbage field pro-

Table 1. Relationship between initial population density $(P i)$ and final population density $(P f)$ of Heterodera cruciferae and reproduction rate $(P f / P i)$ on 'Lupini' cabbage plants, 55 days after inoculation

\begin{tabular}{lcc}
\hline $\boldsymbol{P i}^{\mathbf{a}}$ & $\boldsymbol{P f}$ & $\boldsymbol{P f} \boldsymbol{P} \boldsymbol{i}$ \\
\hline 0 & 0 & 0 \\
0.25 & 0.8 & 3.2 \\
0.5 & 1.5 & 3.0 \\
1 & 2.9 & 2.9 \\
2 & 6.8 & 3.4 \\
4 & 17.0 & 4.2 \\
8 & 36.8 & 4.6 \\
16 & 47.0 & 2.9 \\
32 & 69.6 & 2.8 \\
64 & 184.5 & 2.9 \\
128 & 159.0 & 1.2 \\
256 & 441.4 & 1.7 \\
512 & 692.1 & 1.3 \\
\hline
\end{tabular}

a A single Lupini cabbage plant was transplanted into a $700-\mathrm{cm}^{3}$ clay pot with a potting mixture infested with the appropriate $P i$ (units of eggs and second-stage juveniles per $\mathrm{cm}^{3}$ of soil). Plants were grown in a greenhouse at $20 \pm 2^{\circ} \mathrm{C}$ for 55 days. Data are the average of two trials, each with five replications per each initial nematode population density. 
duction. Conventional chemical control of plant-parasitic nematodes is costly and harmful to the environment; thus, development of resistant germplasm is crucial for the control of these pathogens and is the most economically suitable control (14). Because cabbage varieties resistant to cyst nematodes are not yet available $(32,36)$ and the continuous cropping of cabbage makes crop rotation difficult, control strategies should be focused on reduction of infestation level to below the tolerance limit of the target nematode species (14). Thus, soil solarization, organic amendments, or biological control are preferable, in the context of reduced availability and higher cost of fumigant and non-fumigant nematicides. Soil sampling to assess the risk of nematode damage is necessary for decision making on cropping sequences and the selection of appropriate control tactics.

\section{Literature Cited}

1. Abrantes I. M., Vovlas N., Santos M. S. N. De A., and Espirito Santo S. N. 1994. Meloidogyne arenaria and Plasmodiophora brassicae, causal agents of gall development on cabbage roots in the Republica Democrática de Sao Tomé e Principe. Nematol. Mediterr. 22:115-118.

2. Bello, A., Escuer, M., and Sanz, R. 1999. El género Heterodera en hortalizas en España. Bol. San. Veg. Plagas 25:321-334.

3. Castillo, P., Vovlas, N., Subbotin, S., and Troccoli, A. 2003. A new rootknot nematode, Meloidogyne baetica n. sp. (Nematoda: Heteroderidae), parasitizing wild olive in Southern Spain. Phytopathology 93:1093-1102.

4. Chizhov, V. N., Pridannikov, M. V., Nasonova, L. V., and Subbotin, S. A. 2009. Heterodera cruciferae Franklin, 1945, a parasite of Brassica oleraceae L. from floodland fields in the Moscow region, Russia. Russ. J. Nematol. 17:107-113.

5. Coolen, W. A. 1979. Methods for extraction of Meloidogyne spp. and other nematodes from roots and soil. Pages 317-329 in: Root-Knot Nematodes (Meloidogyne species). Systematics, Biology, and Control. F. Lamberti and C. E. Taylor, eds. Academic Press, New York.

6. Edongali, E. A., and Dabaj, M. 1982. Cauliflower (Brassica oleracea cv. capitata) cyst nematode in Lybia. (Abstr.) Lybia J. Agric. 11:205.

7. Fenwick D. W. 1940. Methods for the recovery and counting of cysts of Heterodera schachtii from soil. J. Helminthol. 18:155-172.

8. Food and Agriculture Organization of the United Nations. 2011. Statistical database (FAOSTAT), 2011. Faostat production statistics of crops. Online database. http://faostat.fao.org/

9. Franklin, M. T. 1945. On Heterodera cruciferae n. sp. of brassicas, and on a Heterodera strain infecting clover and dock. J. Helminthol. 21:71-84.

10. Hussey, R. S., and Williamson, V. M. 1997. Physiological and molecular aspects of nematode parasitism. Pages $87-108$ in: Plant and Nematode Interactions.. K. R. Barker, G.A. Pederson, and G. L. Windham, eds. American Society of Agronomy, Madison, WI

11. Jabbari, H., and Niknam, G. 2008. SEM observations and morphometrics of the cabbage cyst nematode Heterodera cruciferae Franklin 1945, collected where Brassica spp. are grown in Tabliz, Iran. Turk. J. Zool. 32:253-262.

12. Jatala, P., and Jensen, H. J. 1976. Histopathology of Beta vulgaris to individual and concomitant infections by Meloidogyne hapla and Heterodera schachtii. J. Nematol. 8:336-341.

13. Johansen D. A. 1940. Plant Microtechnique. McGraw-Hill Book Co., New York and London.

14. Keinath, A. P., Cubeta, M. A., and Langston, D. B., Jr. 2006. Cabbage diseases, ecology and control. Pages 1-4 in: Encyclopedia of Pest Management. D. Pimentel, ed. Taylor \& Francis, New York.

15. Lewis, S. 1971. Observations on the development of the brassica cyst eelworm. Plant Pathol. 20:144-148.

16. Madani, M., Vovlas, N., Castillo, P., Subbotin, S. A., and Moens, M. 2004.
Molecular characterization of cyst nematode species (Heterodera spp.) from the Mediterranean Basin using RFLPs and sequences of ITS-rDNA. J. Phytopathol. 152:229-234.

17. Mai, W. F., Abawi, G. S., and Becker, R. F. 1972. Population levels of Heterodera schachtii in New York and damage to red table beet and cabbage under greenhouse conditions. Plant Dis. Rep. 56:434-437.

18. McCann, J. 1981. Threshold populations of Heterodera cruciferae and $H$. schachtii causing damage to cabbage seedlings. Plant Dis. 65:264-266.

19. Mennan, S., and Z. A. Handoo. 2006. Plant-parasitic nematodes associated with cabbages (Brassica spp.) in Samsun (Middle Black Sea Region), Turkey. Nematropica 36:99-104.

20. Navas-Cortés, J. A., Vovlas, N., Trisciuzzi, N., Castillo, P., and Troccoli, A. 2010. Anatomical changes induced by two soil-borne pathogens (Plasmodiophora brassicae and Meloidogyne javanica) in cabbage. Nematol. Mediterr. 38:39-43.

21. Potter J. W., and Olthof, T. H. A. 1993. Nematode pest of vegetable crops Pages 171-207 in: Plant Parasitic Nematodes in Temperate Agriculture. K. Evans, D. L. Trudgill, and J. M. Webster, eds. CAB International, Wallingford, UK

22. Rhoades, H. L. 1980. Influence of nematicides and methods of their application on growth and yield of cabbage in sting nematode infested soil Proc. Fla. State Hortic. Soc. 93:246-247

23. Rimmer S. R., Shattuck V. I., and Buchwaldt L. 2007. Compendium of Brassica Diseases. The American Phytopathological Society, St. Paul, MN.

24. Sasanelli, N. 1994. Tables of nematode-pathogenicity. Nematol. Mediterr. 22:153-157.

25. Seinhorst, J. W. 1965. The relationship between nematode density and damage of plants. Nematologica 11:137-154.

26. Seinhorst, J. W. 1979. Nematodes and growth of plants: formulation of the nematode-plant system. Pages 231-256 in: Root-Knot Nematodes (Meloidogyne species) Systematics, Biology and Control. F. Lamberti and C. E. Taylor, eds. Academic Press, London.

27. Seinhorst, J. W., and den Ouden, H. 1966. An improvement of Bijloo's method for determining the eggs content of Heterodera cysts. Nematologica 12:170-171.

28. Sikora, R. A., and Fernández, E. 2005. Nematodes parasites of vegetables. Pages 319-392. in: Plant Parasitic Nematodes in Subtropical and Tropical Agriculture. M. Luc, R. A. Sikora, and J. Bridge, eds. CABI Publishing, Wallingford, UK.

29. Stone, A. R., and Rowe, J. A. 1976. Heterodera cruciferae. CIH Descriptions of Plant-Parasitic Nematodes. Set 6, No. 90. Commonwealth Institute of Helminthology, St. Albans, UK.

30. Subbotin, S. A., Waeyenberge, L., and Moens, M. 2000. Identification of cyst forming nematodes of the genus Heterodera (Nematoda: Heteroderidae) based on the ribosomal DNA-RFLPs. Nematology 2:153-164.

31. Subbotin, S. A., Vierstraete, A., De Ley, P., Rowe, J., Waeyenberge, L., Moens, M., and Vanfleteren, J. R. 2001. Phylogenetic relationships within the cyst-forming nematodes (Nematoda, Heteroderidae) based on analysis of sequences from the ITS regions of ribosomal DNA. Mol. Phylogenet. Evol. 21:1-16.

32. Subbotin, S. A., Mundo-Ocampo, M., and Baldwin, J. G. 2010. Systematics of cyst nematodes (Nematoda: Heteroderinae). Nematol. Monogr. Perspect. $8 B$.

33. Sykes, G. B., and Winfield, A. L. 1966. Studies on Brassica cyst nematode Heterodera cruciferae. Nematologica 12:530-538.

34. Thomason, I. J., and Fife, D. 1962. The effect of temperature on development and survival of Heterodera schachtii Schm. Nematologica 7:139-145.

35. Viane, N. M., Simoens, P., and Abawi, G.S. 1997. SeinFit, a computer program for the estimation of the Seinhorst equation. J. Nematol. 29:474477.

36. White, J. M., and Rhoades, H. L. 1992. Screening cabbage varieties for nematode resistance. Proc. Fla. State Hortic. Soc. 105:321-323. 